\section{Aplicação do Mapeamento Conforme e do software $F(C)$ no estudo de potenciais eletrostáticos complexos}

\author{
Emília de Mendonca Rosa Marques \\ Depto de Matemática, FC, UNESP \\ 17033-360, Bauru, SP \\ E-mail: emilia@fc.unesp.br
}

\title{
RESUMO
}

A lei de Coulomb, Equação (1), descreve a interação entre duas cargas elétricas pontuais $q_{1} \mathrm{e}$ $q_{2}$ separadas por uma distância $r$ num meio de constante dielétrica igual a $k$.

$$
F=\frac{\left(q_{1} q_{2}\right)}{k r^{2}}
$$

A distribuição, contínua, discreta ou uma combinação de ambas, de cargas no espaço leva ao estabelecimento de um campo elétrico e se uma carga é colocada num ponto não ocupado pela carga inicial, a força que age sobre esta carga é chamada intensidade do campo elétrico neste ponto e é dada pela Equação (2), onde $\Phi$ é o potencial eletrostático.

$$
\varepsilon=-\operatorname{grad}(\Phi)
$$

Para uma distribuição de cargas em duas dimensões o campo pode ser descrito através dos seus componentes $E_{x}$ e $E_{y}$, dada pela Equação (3), no domínio dos números Reais e Complexos, respectivamente [1].

$$
\varepsilon=E_{x}+i E_{y}
$$

onde $E_{x}=-\frac{\partial \Phi}{\partial x}$ e $E_{y}=-\frac{\partial \Phi}{\partial y}$

A partir do Teorema de Gauss podemos inferir que deve existir uma função analítica harmônica $\Psi$ conjugada a $\Phi$ tal que:

$$
\Omega(z)=\Phi(x, y)+i \Psi(x, y)
$$

onde $\Omega(z)$ é o potencial eletrostático complexo ou potencial complexo.

Para o desenvolvimento do presente trabalho utilizamos o software $F(C)$ : Funções Complexas, desenvolvido no nosso grupo de pesquisas [2]. O objetivo proposto neste software é a visualização de funções que apresentam variáveis complexas no Plano Complexo, que denominamos Mapa de Cores ou Domínio Colorido. Este mapa é uma distribuição de cores onde à cada ponto desse plano podemos associar um número complexo, e cada uma das cores aparece somente uma vez para um determinado número complexo. As variações nas cores apresentadas coincidem com duas características dos números complexos: o argumento e o módulo [4]. Na Figura (1) apresentamos o Mapa de Cores do plano complexo (ou Domínio Colorido) para o caso da função $f(z)=z$. 
O desenvolvimento do modelo para o campo eletrostático complexo tem um correspondente análogo para o caso de fluxo de fluídos [3]. Para o caso de uma carga $q$ localizada em $z_{0}$, no vácuo, o potencial eletrostático complexo é dado pela Equação (5).

$$
\Omega(\mathrm{z})=-2 \mathrm{q} \ln \left(\mathrm{z}-\mathrm{z}_{0}\right)
$$

Na Figura (2) apresentamos o Domínio Colorido da função dada na equação (5) para o caso onde $q>0$, representando uma fonte e na Figura (3) para $q<0$, representando um sumidouro em analogia ao fluxo de fluídos.

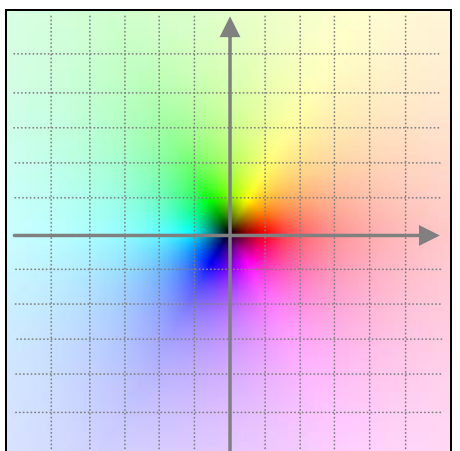

Figura 1.

Domínio Colorido da função $f(z)=z$.

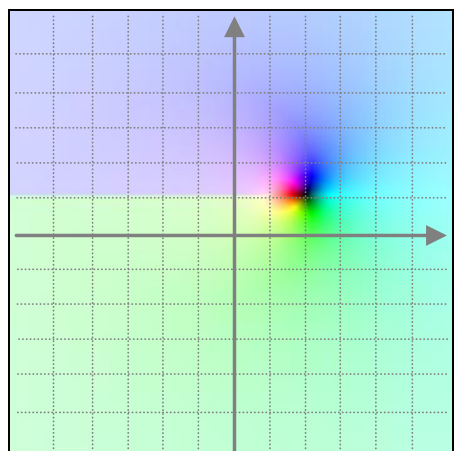

Figura 2.

Domínio Colorido da função $\Omega(z), q=1, z_{0}=1+i$.

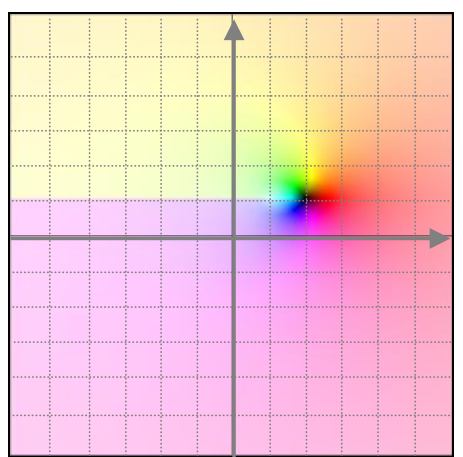

Figura 3.

Domínio Colorido da função $\Omega(z), q=-1, z_{0}=1+i$.

Podemos verificar pela análise das Figuras 2 e 3 que o método dos Mapas de Cores para o plano complexo pode ser muito útil no estudo de sistemas de interesse físico como o de potencial eletrostático.

As figuras apresentam também uma característica comum que é a presença da mudança brusca de cor o que evidencia a presença de uma folha de Riemann. Esta é uma característica importante dos potenciais complexos que é de difícil visualização, sendo possível, entretanto com a abordagem adotada neste trabalho.

Palavras-chave: Domínio Colorido, Função Complexa, Software Gráfico

\section{Referências}

[1] G. Ávila, "Variáveis Complexas e Aplicações", Livros Técnicos e Científicos, Rio de Janeiro, 2000.

[2] E. L. da Silva; A. R. de Souza; E; M. R. Marques, "Números e Funções Complexas: Representação e Interpretação Gráfica", Cultura Acadêmica Editora, São Paulo, 2008.

[3] E. L. da Silva, A. R. de Souza, E. M. R. Marques, Alguns estudos de fluxo de fluido utilizando software gráfico, Revista Brasileira de Ensino de Física, 31 (2009) 3501-3509.

[4] T. Needham, "Visual Complex Analysis", Claredon Press, Oxford, 1997. 